\title{
A contribuição da Logosofia para a docência na Educação Física
}

\author{
DIAS, Gabrielle Batista ${ }^{1}$ \\ FERREIRA, Nilza Fátima Virgem² \\ TOCAFUNDO, Ronan Daré ${ }^{3}$
}

\section{RESUMO}

A Pedagogia Logosófica é fundamentada pela busca do conhecimento de si mesmo. Dotado dessa ideia, buscou-se como essa Pedagogia pode contribuir para superar possíveis desafios da docência no século XXI. Considerando a Educação Física como uma profissão recentemente regulamentada, experiências docentes desse setor tornam-se um campo experimental excelente para destacar grandes desafios de superação e reconhecimento dentro da escola. O objetivo deste estudo foi conhecer a atuação do professor de Educação Física dentro do Sistema Logosófico. Aplicando um questionário aos Professores de Educação Física do Sistema Logosófico de Educação, analisando e tabulando, obteve-se resultados que indicam que os Professores consideram o conhecimento e o estudo da Logosofia como auxiliador fundamental na boa condução das aulas.

Docência. Professor. Educação. Logosofia. Educação Física.

\section{The contribution of Logosophy to teaching in Physical Education}

\section{ABSTRACT}

The Logosophical Pedagogy it's based, on the search for knowledge of oneself. Endowed with this idea, we sought how this Pedagogy can contribute to overcome possible challenges of teaching in the 21st century. Considering Physical Education as a newly regulated profession, teaching experiences in

\footnotetext{
1 Pós-graduanda em Docência na Educação Básica no IFMG. Professora de Educação Física. Professora de Ginástica Artística na Educação Básica. E-mail: gabrielle.batistadias@gmail.com. Lattes: http://lattes.cnpq.br/6726445835872980. ORCID: https://orcid.org/0000-0002-4972-9981.

2 Pós-graduanda em Docência na Educação Básica no IFMG. Servidora Pública da Prefeitura Municipal de Ouro Preto. Graduação em Geografia pelo Instituto Federal Minas Gerais (IFMG). E-mail: niferreira.geo@gmail.com. Lattes: http://lattes.cnpq.br/6470637983892451. ORCID: https://orcid.org/0000-0003-1827-4504.

${ }^{3}$ Doutor em Educação pela Faculdade de Educação da Universidade Federal de Minas Gerais (FaE-UFMG). Mestre em Educação Tecnológica pelo Centro Federal de Educação Tecnológica de Minas Gerais (CEFET-MG). Professor no Programa de Mestrado Profissional - PROFEPT. Coordenador do Programa Institucional de Bolsas de Iniciação a Docência (financiado pela CAPES) PIBID, Área: Física, IFMG/Congonhas. E-mail: ronan.dare@ifmg.edu.br. Lattes: http://lattes.cnpq.br/9214890648714773. ORCID: https://orcid.org/0000-0003-4320-0435.
}

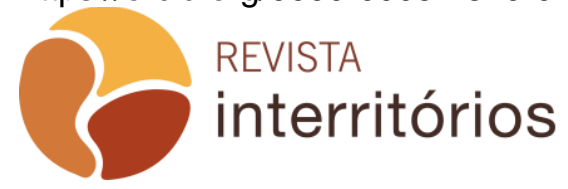

Interritórios | Revista de Educação Universidade Federal de Pernambuco, Caruaru, BRASIL | V.5 N.9 [2019] 
this sector become an excellent experimental field to highlight major challenges of overcoming and recognition within the school. The objective of this study was to know the performance of the Physical Education teacher within the Logosophical System. Applying a questionnaire to the Physical Education Teachers of the Logosophical Education System, analyzing and tabulating, we obtained results indicating that the teachers consider the knowledge and study of Logosophy as a fundamental helper in the good conduct of the classes.

Teaching. Teacher. Education. Logosophy. Physical Education.

\section{Il contributo della logosofia all'insegnamento nell'educazione física}

\section{RIASSUNTO}

La pedagogia Logosofica si basa sulla ricerca della conoscenza di se stessi. Dotato di questa idea, abbiamo cercato come questa Pedagogia puo contribuire a superare le possibili sfide dell'insegnamento nel $21^{\circ}$ secolo. Considerando l'Educazione Fisica come una professione recentemente regolamentata nel Brasile, le esperienze di insegnamento in questo settore diventano un eccellente campo sperimentale per evidenziare le principali sfide del superamento e del riconoscimento all'interno della scuola. Lo scopo di questo studio 'e di conoscere le il lavoro dell'insegnante di educazione fisica all'interno del Sistema logosofico. Applicando un questionario agli Insegnanti di Educazione Fisica del Sistema di Educazione Logosofica, abbiamo ottenuto risultati che indicano che gli insegnanti considerano la conoscenza e lo studio della Logosofia come un aiuto fondamentale nella buona condotta delle lezioni.

Insegnamento. Maestro. Istruzione. Logosofia. Educazione física.

\section{La contribución de la Logosofía a la enseñanza en Educación Física}

\section{RESUMEN}

La Pedagogía Logosófica se funda en la búsqueda del conocimiento de uno mismo. Dotados de esta idea, buscamos cómo esta pedagogía puede contribuir a superar los posibles desafíos de la enseñanza en el siglo XXI. Considerando la Educación Física como una profesión recién regulada, las experiencias de enseñanza en este sector se convierten en un excelente campo experimental para resaltar los principales desafíos de superación y reconocimiento dentro de la escuela. El objetivo de este estudio fue conocer el desempeño del maestro de Educación Física dentro del Sistema Logosófico. Aplicando un cuestionario a los maestros de educación física del sistema de educación logosófica, analizando y tabulando, obtuvimos 
resultados que indican que los maestros consideran el conocimiento y el estudio de la logosofía como un ayudante fundamental en la buena conducta de las clases.

Enseñanza. Profesor. Educación. Logosofía. Educación Física.

\section{INTRODUÇÃO}

$\mathrm{O}$ atual contexto de uma sociedade cada vez mais exigente em que as mudanças são constantes e têm influenciado diretamente 0 meio educacional, ao oferecer diversas possibilidades de educação formal, que vão de alternativas que se atêm a ensinar o conhecimento contido na formação curricular básica comum, as opções que vão além.

Sabe-se que o professor tem um papel significativo na formação da sociedade, contribuindo com seus saberes, seus valores e suas experiências para o desenvolvimento humano. Para diversos autores como Malacrida e Barros (2013), D’Ávila e Sonneville (2012) e Imbernón (2009), a preocupação da educação deve ser pautada no desenvolvimento intelectual perfazendo o desenvolvimento humano e moral do educando, de tal maneira que esse sujeito do processo de ensino se sobressaia na sociedade.

Neste contexto, cabe ao professor lidar com os acontecimentos e dinâmicas que envolvem a sociedade buscando selecionar conteúdos e criar estratégias para abordar os temas propostos em sala de aula ajustando a teoria e a prática, o que configura um grande desafio para o educador que busca um diferencial na educação e consequentemente na vida.

Para a atuação mais logosófica na Educação Física, é necessário que o Professor esteja presente inteiramente dentro da sala de aula. Não é possível que uma correção seja consciente, caso o Professor não crie vínculos com o estudante. E a necessidade de vínculo se justifica na situação que as correções feitas, não tenham efeito de curto prazo a sim médio, prazo e sim a longo prazo. Para essa atuação de modo constante, há a necessidade da prática, do empenho e a constância a se opor diante a correção inconsciente que não gere frutos futuros positivos. Uma prática desse exercício permite a aplicação exitosa do método.

\section{Referencial Teórico}

Logosofia 
O que pode ser feito para que cada um se conheça melhor? A Logosofia não oferece resposta a essa pergunta, mas o estudo dela proporciona condições no indivíduo para que cada um possa buscar o conhecimento de si mesmo e obter possíveis respostas de diversos setores na vida. E essas respostas que podem mudar de acordo com a vida que se leva, facilitam o processo de evolução consciente interna, proporcionando uma melhor sociedade.

Criada pelo pensador e humanista argentino Carlos Bernardo González Pecotche, a adoção da palavra Logosofia em 1930, que é de origem grega tem sua raiz etimológica fundamentada em "ciência da razão", representando todos os estudos dessa ciência que foram realizados, tendo por finalidade à busca do conhecimento do mundo mental, a consciência, as capacidades (às vezes, ocultas) de si mesmo.

No dia 11 de Agosto comemora-se o Dia Mundial da Logosofia, data de nascimento do seu Fundador, que mesmo após a sua morte em 04 de abril de 1963, seus conhecimentos continuaram a ser difundidos, através de diversos centros de estudos e Institutos Logosóficos foram sendo criados destacando assim suas obras como um legado de evolução à humanidade.

A Logosofia de acordo com González (2001) tem a sua estrutura baseada na formação biopsicossocial e dentro dela existem três sistemas que regem a estrutura e funcionamento do ser humano: o primeiro sistema é o Mental, que é composto pela mente, permiti o pensar, o recordar, o julgar, imaginar e todas as faculdades que a esse sistema cabe; outro sistema é o Sensível "órgão sensível por excelência e centro regulador da vida psíquica do homem" (GONZÁLEZ, 2013, p. 73); e o sistema Instintivo, que "sua definição e atividade como força energética" (GONZÁLEZ, 2013, p. 79). Ressaltando que cada separação da Logosofia tem em si uma finalidade específica, que é aproximar o conhecimento do homem.

Neste contexto, buscar conhecer os pensamentos é a base para um estudante de Logosofia. Mas como essa ação de conhecimento de si mesmo pode auxiliar na docência de um professor? Segundo a Logosofia ao dedicarse a esse estudo o ser humano se torna mais capaz de conhecer seus pensamentos e se aproximar da superação humana, que é o lema que a Fundação carrega consigo.

A Pedagogia Logosófica uma linha pedagógica que sobressalta conceitos válidos na Logosofia que perpassam pelos conceitos de vida, de liberdade, de defesas mentais, de pensamentos, de leis universais, de conhecimento de si mesmo, e tudo isso aliado ao apoio da sensibilidade humana. Sempre buscando encontrar soluções dentro de si para depois 
contribuir com seus semelhantes, explorando o campo do autoconhecimento, sendo capaz de identificar, classificar e selecionar os próprios pensamentos.

O conhecimento do mundo pode ter a sua origem nos pensamentos que são gerados no dia a dia, devido a essa situação que na Logosofia é necessário estar consciente ao máximo dos pensamentos na mente e nossas ações correspondentes.

$\mathrm{Na}$ busca da evolução consciente quando há decisão de retomar a própria existência, deixando de viver por viver, a Logosofia como ressalta González (2012), destaca as deficiências psicológicas, que são pensamentos que determinam ou causam impotência no esforço de ser melhor. Esse autor complementa ainda, que para cada deficiência propõe-se uma antideficiência que atua sobre o pensamento negativo na intenção de trazer mais sensibilidade ao ser e atuar com mais compreensão consigo mesmo e com o próximo. Assim, dentro de sala de aula é necessário que o professor crie vínculo com o aluno, pois somente assim haverá uma correção consciente do aluno e consequentemente essa correção terá efeito de médio, longo prazo.

De acordo com González (2013), o Método Logosófico se divide em três partes: Método de Exposição, Método de Aplicação e Método de Aperfeiçoamento, que são combinadas objetivando além do aprendizado comum à todas as escolas, objetivos que são inerentes a Logosofia, assim "cada ensinamento Logosófico é de per si parte inseparável do método, e todos, sem exceção, convergem para o mesmo fim." (GONZÁLEZ, 2013, p.103). No Método de Exposição se tem ordenamento dos estudos logosóficos e que em uma mente constantemente descobrirá conexões que se justificam. No Método de Aplicação, respeita o livre arbítrio e considera as diferentes capacidades e níveis de evolução. Por último o Método de Aperfeiçoamento, assimilação mental do conhecimento corrigindo-se e auxiliando os alunos a corrigirem ativamente os pensamentos e que haja correções oportunas e bons resultados.

É constante a busca do ser humano por uma motivação externa, mas com o Método Logosófico, a motivação deve ser encontrada dentro de si mesmo, funciona como uma lanterna, uma luz que vira para si próprio, buscando soluções internas, "os conhecimentos que haverão de iluminá-la" (GONZÁLEZ, 2016). Neste contexto, pode-se dizer que dentro dos Colégios Logosóficos há uma atuação constante de estímulos aos estudantes que busquem sempre olhar para dentro de si buscando conhecimentos vitais de sua evolução.

Para a conscientização do campo experimental, González (2013) ressalta a necessidade de assumir uma participação ativa no próprio mecanismo interno e na organização dos pensamentos. Nesse campo 
experimental existem quatro espaços que se complementam: o mundo interno, o mundo Logosófico, o mundo corrente e o mundo metafísico. Sendo eles, o mundo interno que é condizente com as constatações conscientes e registro dos fatos; o mundo Logosófico, centros de estudos que há verificações e intercâmbios de situações que são expostas por seus frequentadores; o mundo corrente, se detém nas observações focadas nos estados psicológicos e mentais dos que estão a nossa volta, e o mundo metafísico no qual se completam a experiências dos outros mundos, intimamente relacionado com o mundo interno, "mas requer tempo, paciência e saber" (GONZÁLEZ, 2013, p.110).

Para o melhor aproveitamento e conscientização da Logosofia como Professor, segundo o site da Logosofia no Brasil, há um conceito que "pela experimentação do que se estuda e pelo estudo do que se experimenta, [...] movimento recíproco [...] que vão se formando o patrimônios dos bens eternos" que se envolvem as correções conscientes e ativas dentro de uma sala de aula.

\section{Educação Física}

Segundo Gaya, Gaya (2013) a Educação Física considerada em seu perfil de Cultura Corporal do Movimento, pode ultrapassar os determinismos físicos e biológicos. Diante essas características da Educação Física Escolar e da Logosofia o artigo assume a função de demonstrar registros e estudos que fundamentem na vida do discente a construção de um ser mais consciente e ativo em sua vida, proporcionando assim condições para o melhor crescimento integral, biopsicossocial da criança. Essa produção ressalta a atuação do Professor como indispensável para agregar e conscientizar o aprendizado do estudante, uma vez que as crianças ainda no fundamental 1, não possuem todos campos experimentais desenvolvidos para a retenção consciente de alguns aprendizados.

A tarefa da Educação Física, segundo Betti (2002), enquanto componente escolar, é introduzir e integrar o aluno na cultura corporal de movimento. Caracterizado por uma disciplina de aquisição do conhecimento através de movimentos conjuntamente com processos cognitivos, afetivos e psicomotores. Em uma definição básica, mas não tão simples, nosso material de estudo é o corpo e tudo com o que ele se relaciona, e com as repercussões nas mais diversas áreas existentes. A Educação Física Escolar é uma disciplina "que deve dar conta da dimensão Corporal da vida e humana", como afirma Filho, (2017). A Educação Física Escolar mesmo 
sendo um componente curricular da Educação Básica, ainda pode ser encontrada as margens das escolas.

Por inúmeros fatores essa condição margeada da disciplina favorece a construção da imagem de uma aula que qualquer outro professor poderia ministrar, bastando apenas gostar de esportes, assim como relatado em Rezer e Fensterseifer, (2008). Ainda segundo esse artigo, uma possível solução para a conquista de maior valorização da disciplina, seria a conscientização dos professores de tamanha complexidade, e como consequência os estudantes e os outros Professores também teriam essa consciência.

Essa complexidade poderia atingir os diversos espaços da Educação Física, sendo no período da graduação, seja na pós. Essa elevação do conhecimento estenderia em estudos para os professores e/ou também para os alunos. Mesmo que essa conscientização seja lenta, por ser um processo que envolve várias etapas do ensino e envolvimento dos pensamentos e que muitas vezes essas etapas não estão diretamente relacionadas, essas mudanças precisam ser efetiva para a caracterização da disciplina, faz-se necessário aos professores uma presença protagonista no processo do ensino, uma aula, que segundo Betti (1995), seja um desafio realizável a eles.

\section{O que é ser professor no século XXI}

Ao refletir sobre o que é ser professor no século XXI, a primeira iniciativa é observar as transformações que a sociedade tem passado ao longo dos séculos, buscando compreender a influência dessas mudanças no contexto educacional, principalmente no exercício da docência, que de acordo com Tardif (2008), é compreendida por muitos autores como um trabalho cognitivo, que objetiva favorecer a aquisição de uma cultura, permitindo a construção do conhecimento, tendo como centro do seu exercício o trabalho sobre e com seres humanos.

Tardif (2008) nos seus estudos sobre a organização escolar coloca que escola em sua atividade de ensino se manteve por um bom tempo em segundo plano, e só passa a ser vista sobre um novo olhar com o avanço da sociedade, ao sentir a necessidade de compreender as suas transformações. No entanto, a questão fundamental não era o conhecimento em si, mas principalmente preparar os indivíduos para as novas demandas do mercado de trabalho. 
Malacrida e Barros (2013, p. 46) pontuam que as transformações da sociedade "não se trata apenas de mais uma crise conjuntural do modelo capitalista", mas também "do surgimento de novas formas de organização social, econômica e política", Imbernón $(2009$, p. 19) complementa que a sociedade passava por "uma evolução acelerada [...] em suas estruturas materiais, institucionais e formas de organização da convivência, modelos de família, de produção e de distribuição", o que era impossível de não afetar os indivíduos no seu modo de viver, pensar, sentir e agir nesse contexto.

Zwicker (2017) ressaltar que as novas tecnologias da informação influenciam na vida da sociedade como um todo, pois o acúmulo de informações, a velocidade na transmissão, a superação das limitações espaciais, a utilização da multimídia, todo um contexto é modificado trazendo consigo impactos também no meio educacional.

Para Imbernón (2009, p. 19), todas essas mudanças "puseram em crise a transmissão do conhecimento de forma tradicional (textos, leituras, etc.) e, portanto, também as instituições que se dedicam a isso", esse autor complementa que a educação "já não é mais patrimônio exclusivo dos docentes", ela compete a toda comunidade e aos meios de que se dispõe a essa finalidade, transformando a prática da educação, ou seja, a educação que acontecia naquele espaço da escola fechado se expandiu a outros espaços, a outras formas.

Corrobora-se com Zwicker (2017, p. 50), ao colocar que "hoje o aprender não se prende a espaço ou tempo determinado", "nem a um detentor/transmissor de informações", "e muito menos, a um aluno passivo". Ferramentas tecnológicas abrem possibilidades para que o conhecimento não se restrinja somente a uma sala de aula, e modifica a atitude do professor, que busca não focar só em passar conteúdo ou transmitir saberes prontos e imutáveis, o professor torna-se mais um mediador de conhecimento.

De acordo D'Ávila e Sonneville (2012, p. 34), "a atividade docente é uma prática social complexa que combina atitudes, expectativas, visões de mundo, habilidades e conhecimentos", exigindo-se para o seu exercício a formação profissional, conhecimentos específicos, aquisição de habilidades para melhor exercê-la.

Desta forma Luckesi (2011), mostra a importância de se pensar uma prática docente que busque um ensino e aprendizagem em que os educandos aprendam a se desenvolver tanto individual como coletivamente, o que se efetivará através de um trabalho docente que seja significativo tanto para o aluno, quanto para o próprio professor, sendo fundamental que esse professor desenvolva um trabalho que faça com que o aluno deseje está em 
uma sala de aula, "que Ihes demonstre o significado e o prazer de seu próprio desenvolvimento" (LUCKESI, 2011, p. 140).

Assim, nesse contexto atual em termos de educação é necessário repensar o sistema educacional como o todo, inclusive a formação dos docentes, é necessário romper com tudo que leve a pensar a educação de um modo linear, é preciso um modo de pensar mais abrangente, que busque integrar com novas formas de ensinar, de aprender, de organizar, abrir-se ao novo, ao diferente. Assim, complementa-se com Moreira (1999), ao colocar que para Vygotsky o desenvolvimento cognitivo não pode ser entendido sem observar o contexto social e cultural em que ele ocorre, e propõem que os processos que levam ao aprendizado e ao desenvolvimento devem ser repensados adequando-se às novas condições do contexto social.

É importante frisar que a educação tornou-se um grande desafio e a figura do professor torna-se um dos grandes responsáveis na formação dos indivíduos para lidar com eles, pois segundo Lima (2012), o professor não tinha o hábito de refletir sobre si, sobre seu saber, sobre o seu fazer, sua prática, e agora mais do que nunca é necessário essa reflexão, o professor precisa conhecer a sua forma de dar aula, a sua forma de instruir, ensinar, e Lima (2012, p. 142) vai muito além ao enfatizar que o professor "deve refletir também sobre seu próprio processo de aprendizagem". Antigamente o professor tinha a sensação de que ao formar já estava preparado para a docência, mas hoje a realidade é totalmente diferente, é necessário cada vez mais conhecimento, assim, a docência é construída no dia a dia do seu exercício através de uma junção do conhecimento teórico aliado ao conhecimento prático.

Nessa atual conjuntura a sala de aula torna-se um ambiente para a ação do professor, tornando-se um verdadeiro campo experimental, um laboratório de compartilhamento, onde ao mesmo tempo em que o professor ensina o conteúdo, ele tem a oportunidade de adquirir mais conhecimentos, além de refletir sobre suas ações. Assim, o processo de formação de professores é algo contínuo, "multifacetado, plural, tem início e nunca tem fim" (VEIGA, 2010, p. 15).

Corrobora-se com Luckesi (2011), ao enfatizar que cabe ao professor pesquisar e refletir sobre sua ação docente, construindo saberes que lhes permitam aprimorar o seu fazer docente, ressaltando que ao longo do tempo no exercício da docência o professor vai adquirindo experiências, e precisa se conscientizar sobre a própria prática, evitando automatizar ou mecanizar o modo de dar aula, através da reflexão de sua ação, em suas atividades cotidianas, nas situações em que o professor se depara, e são necessárias decisões, construindo seus saberes pela ação e também pela reflexão. 
Como a Logosofia favorece a Docência no Século XXI

Ao realizar uma pesquisa com alunos de segundo e terceiro grau para conhecer a percepção dos mesmos sobre o que seria um "Bom Professor" Cunha (2011, p. 61), relata que "entre as expressões usadas estão "é amigo", "compreensivo", "é gente como a gente a gente", "se preocupa conosco", "é disponível mesmo fora da sala de aula", "coloca-se na posição do aluno", "é honesto nas observações, "é justo", etc". Dessa forma é perceptível, que a questão afetiva tem grande representatividade na vida dos alunos, ou seja, o aluno não vê o professor somente como um profissional que está ali para cumprir sua função, mas como alguém que faz parte da sua vida, que se preocupa com ele.

Assim, outro aspecto destacado por Cunha (2011), é a questão do relacionamento do professor com a sua área de conhecimento, pois o mesmo é observado o tempo todo por seus alunos, assim as suas atitudes em sala de aula, na prática, ao mostrar o seu interesse pela disciplina que leciona, que gosta do que faz, do que ensina, isso motiva os alunos, o professor consegue atrair a atenção até dos alunos que não gostam da disciplina, ele consegue cativar esses alunos.

Deve-se levar em conta também a metodologia adotada pelo professor, Cunha (2011, p. 30), mostra a importância do professor conhecer o conteúdo abordado, saber repassar as informações, conseguir fazer com que o seus alunos aprendam o conteúdo, assim para esses alunos os melhores professores são os que [...] "tornar as aulas atraentes", "estimula a participação do aluno", "sabe se expressar de forma que todos entendam", "induz à crítica, à curiosidade e à pesquisa", "procura formas inovadoras de desenvolver a aula", "faz o aluno participar do ensino" etc.", ou seja o professor precisa ser um diferencial na vida dos alunos, preocupar com a aprendizagem dos mesmos.

É preciso desmistificar o paradigma de que um bom professor é aquele que aprova todo mundo, que distribui "pontinhos", que deixa o aluno fazer o que quer dentro da sala de aula, que não tem controle, essa percepção de professor bom está totalmente errada, nem os próprios alunos enxergam essa atitude como de bom professor. Cunha (2011, p. 63) coloca que, "[...] o aluno valoriza o professor que é exigente, que cobra participação e tarefas [...]". O bom professor é aquele que efetivamente se preocupe com que $o$ aluno aprenda se desenvolva, se sobressaia nos estudos.

Característico de um bom professor é aquele que ensina com bondade, conhecer os ensinamentos da Logosofia favorece a se apropriar

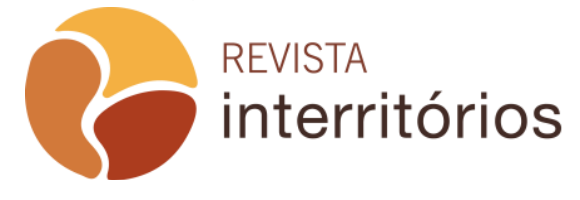

Interritórios | Revista de Educação Universidade Federal de Pernambuco, Caruaru, BRASIL | V.5 N.9 [2019] 
dessa bondade. Vincular ao que se ensina desperta interesse no aprendizado reanima a alma e cria estímulos de aprendizagem. Conscientizar que o estudo não há um fim se justifica sempre na busca do melhor de si mesmo. Para uma ampliação e apropriação da arte de ensinar devemos estar sempre aprendendo, retroalimentando assim o ciclo de ensino e aprendizagem que pode suprir falhas e contribuir para superação dos desafios dos professores no século XXI.

Não pode ensinar o que não se tem conhecimento, longe desse pequeno artigo ensinar tudo sobre Logosofia, mas bem perto se encontra de demonstrar a oportunidade de um estudo que permite aprimorar a ação docente dos Professores contemporâneos. A bondade que se incentiva nos Ensinos Logosóficos são fontes inesgotáveis de afeto e aprimoramento da profissão de Professor. Como citado anteriormente o interno é o maior e melhor campo experimental, o que os professores tem aprendido conscientemente. Tendo como resposta a origem pela busca constante do conhecimento para o caminho com firmeza e segurança no ensino dos estudantes e contribuições para a correção consciente.

\section{Metodologia}

Esse trabalho constitui uma análise sobre a visão dos Professores de Educação Física que atuam no Sistema Logosófico de Ensino e como o estudo da Logosofia pode auxiliar sobre os desafios de ser professor no século XXI. Conjuntamente com a análise, foram colocados sobre a luz de estudos posicionamentos de diversos autores sobre esse desafio do exercício da docência.

Sabe-se que a pesquisa bibliográfica, de acordo com Köche (2011), tem o objetivo de colocar o pesquisador em contato direto com tudo que foi escrito, dito ou filmado sobre o assunto a ser estudado. Assim, para a realização deste trabalho, iniciou-se um levantamento de dados, através de pesquisa bibliográfica, a fim de se analisar as principais contribuições teóricas existentes no campo de estudo da Docência, Educação Física e da Logosofia para superação dos desafios de ser docente no século XXI.

Desta forma, essa pesquisa abrangeu fases distintas e interligadas: Fase 01, pesquisa e fundamentação para a elaboração do questionário, que foi montado através da plataforma Formulários Google; Fase 02, envio do link do questionário para 31 (trinta e um) professores de Educação Física do Sistema Logosófico de todo Brasil e também da Argentina, através do aplicativo Whatsapp. Os Professores possuíam tempo de experiência diversos e sendo a maioria do Ensino Fundamental; Fase 03, o recebimento 
de 12 (doze) questionários respondidos através da plataforma Formulários Google e elaboração dos gráficos com o resultado e categorização das respostas. Fase 04, finalização do artigo.

O levantamento de dados foi realizado através da aplicação de um questionário composto de dez questões, sendo cinco questões objetivas e cinco dissertativas. As perguntas dissertativas buscaram conhecer um pouco mais do modo como o estudo de Conceitos Logosófico pode auxiliar na formação e atuação dos Professores de Educação Física Escolar no Sistema Logosófico de ensino.

Dentro das questões, buscou-se conhecer possibilidades de atuação e pequenos relatos de situações que os profissionais passaram em relação ao tema Educação Física e Logosofia - Superando os desafios na docência. $\mathrm{Na}$ pesquisa em questão, o enfoque foi o estudo de como os professores da disciplina Educação Física compreendem o auxílio da Logosofia na formação e como aplicam a mesma na sua atuação docente em sala de aula.

\section{Resultados e Discussões}

Ao analisar os desafios de se exercer a docência no contexto atual, adentrou-se inicialmente o lugar que mais define tal profissão: a escola, o ambiente escolar e seu espaço físico com suas características. Recorre-se a Tardif (2008), ao colocar que a docência moderna desde sua existência ocorreu na escola, em um lugar organizado, espacial e socialmente separado de outros espaços da organização social, representando muito além de um espaço físico, mas também um espaço social onde se realiza o trabalho do professor. Neste contexto, busca-se conhecer a atuação do professor de Educação Física dentro do Sistema Logosófico de Ensino, procurando entender como a Pedagogia Logosófica pode contribuir para superar os desafios de se exercer a docência no século XXI.

A pesquisa contou com a participação de doze professores, dos quais onze permanecem trabalhando no Sistema Logosófico de Educação. Apenas um professor não atua mais no sistema, porém motivos para a saída, não foram levantados no questionário. Destaca-se que $50 \%$ dos pesquisados, possuem mais de dez anos de experiência na docência no Sistema Logosófico de Ensino, conforme demonstrado no Gráfico 1.

Para essa pesquisa, esse fato torna-se interessante, pois são opiniões de professores que possuem muito tempo de experiência na prática docente, e podem contribuir amplamente para a construção de saberes da Educação Física, solidificando a qualificando essa profissão recente. 


\section{Gráfico 1 - Tempo de docência no Sistema Logosófico}

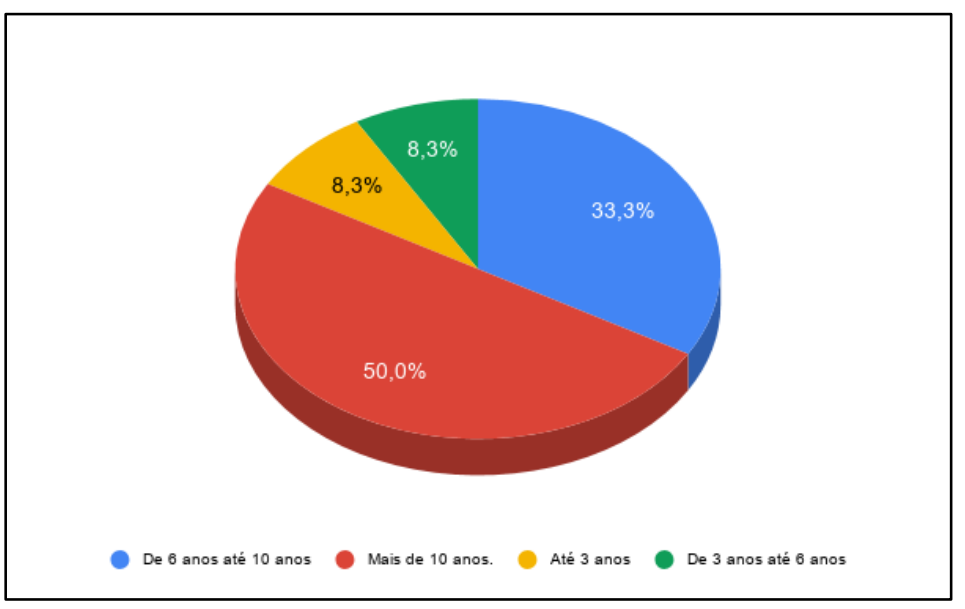

Fonte: Autores.

Para entender um pouco como ocorre a atuação desses professores de Educação Física, qual o público que os mesmos lidam no dia a dia, a faixa etária desses anos, foi perguntado ao professor qual o seu ensino de atuação, e assim como exposto no Gráfico 2, a maioria dos professores estão trabalhando com crianças, sendo que $41,7 \%$ dos professores estão exercendo a docência no Ensino Infantil, ou seja estão trabalhando com crianças com idade até os cinco anos, que estão no início da formação, começando a conhecer o mundo, desenvolvendo 0 processo de aprendizagem. E 41,7\% estão trabalhando com o Ensino Fundamental I, que compreende crianças de 5 a 10 anos, que também estão em processo de formação, que exige um acompanhamento mais de perto do professor.

Para os professores de Ensino Fundamental II e do Ensino Médio, foram $8,3 \%$ dos pesquisados para cada um dos segmentos.

\section{Gráfico 2 - Ensino de atuação}

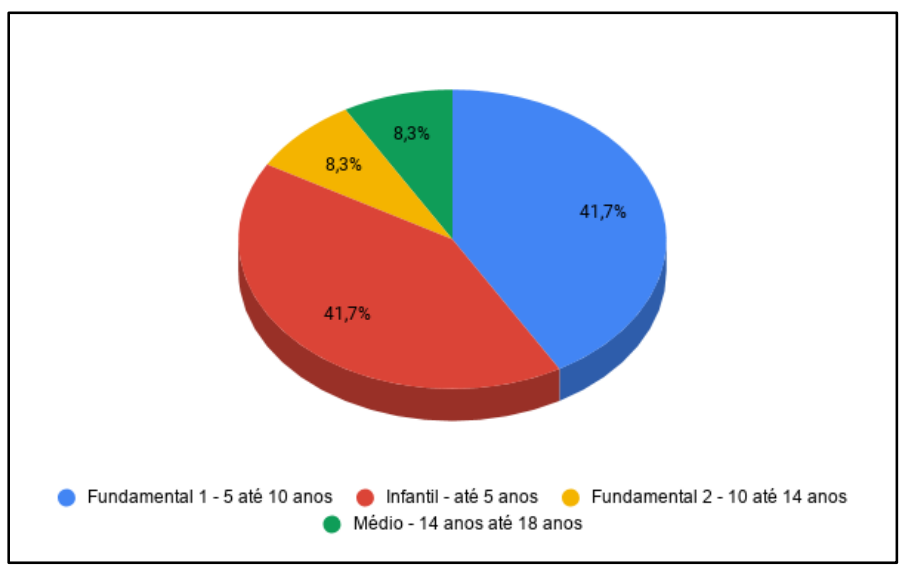

Fonte: Autores. 
O processo de formação é essencial para atuação do Professor, uma vez que sem ele não se pode lecionar. Para o exercício da docência, anos de estudos são dedicados às mais diversificadas temáticas da Educação Física. Foi questionado aos pesquisados "se a estrutura de ensino aprendida durante a graduação foi suficiente para a atuação dentro das Quadras das escolas", e como mostra no Gráfico 3, 91,7\% dos professores responderam que não. $O$ que permite constatar que se 0 processo de formação do professor é incompleto, isso contribui para que a docência seja cada vez mais desafiadora, e pode-se pontuar como exemplo a dificuldade de muitos professores aliarem a teoria à prática. Como colocado por Imbernón (2009), muitas vezes o professor tem "conteúdo", mas durante o percurso de atuação, destaca a dificuldade de colocar em prática o que foi ensinado durante a graduação e, também, a dificuldade de encontrar referências e fontes confiáveis de acesso para construção de um conteúdo para inserção à realidade dos alunos. Segundo a BNCC, há para Educação Física, seis temáticas sendo elas Brincadeiras e Jogos, Esportes, Ginásticas, Danças, Lutas e Práticas corporais de aventura.

\section{Gráfico 3 - A estrutura de ensino aprendida durante a graduação foi suficiente para atuação dentro das Quadras das Escolas}

Fonte: Autores.

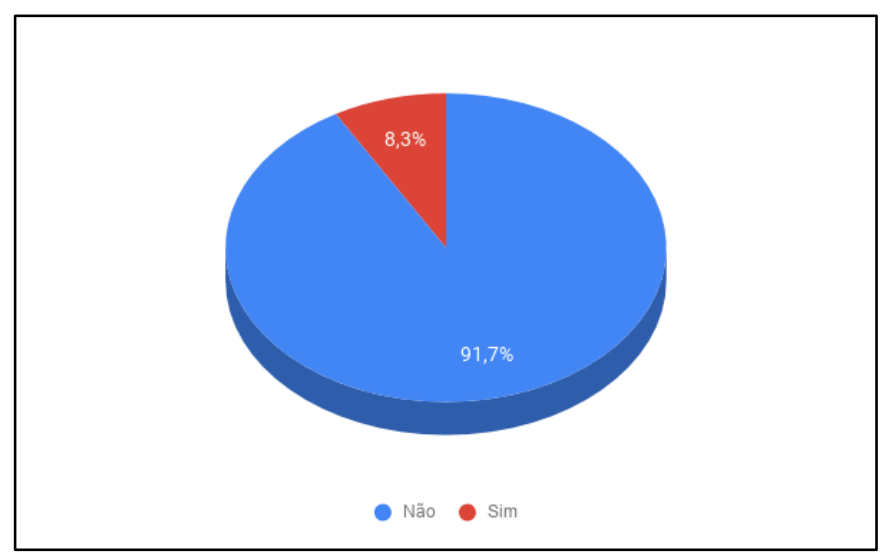

De acordo com Freitas (2017), no início da sua docência, ela se deparou com muitas inquietudes internas que refletiam em sala de aula. Enquanto professora, ela sabia o que queria para a vida de seus alunos, porém, ela não sabia como transformar essas inspirações em realidade. Para Freitas (2017), o ideal era uma escola "que contemplasse de um lado a excelência do currículo escolar com todos os conteúdos a serem ensinados e, do outro lado, o exemplo de vida que o professor passa para o aluno, preparando-o para governo da própria vida". 
Desta forma, essa inspiração fez com que Freitas (2017) buscasse cada vez mais conhecimento, até o momento em que the foi apresentada a Pedagogia Logosófica, uma ciência formativa da individualidade que permite o domínio consciente das possibilidades humanas - o que poderia ser "um elemento valoroso na arte de ensinar", despertando o seu interesse em aumentar seu estudo e em experimentar a Logosofia.

Neste trabalho sobre a Pedagogia Logosófica, busca-se mostrar que ela pode ajudar a superar os desafios da docência, porque quando indagamos ao professor "Defina o significado de Logosofia para você", é surpreendente como os conceitos de assemelham, destacando palavras como: desenvolvimento humano, conhecimento de si, superação individual, evolução constante, educar o ser para vida, que são valores que o professor anseia para seus alunos.

Como afirma González (2012), "aquele que busca o conhecimento por simples cultivar, não evita que se sinta um vazio após o término dele, gera resultados sem objetos perduráveis." Mas aos que buscam o conhecimento substancial, a busca continua em qualquer lugar onde se encontra. "O exercício de tão elevada docência é uma arte em que estão resumidas as virtudes mais elevadas" e suas virtudes se encontram na alma cuja tenha instrução completa e integral.

Para Libâneo (2011), é necessário que a escola seja um espaço de integração e síntese, considerando o contexto atual globalizado, transnacional, que exige dos indivíduos uma leitura crítica das transformações que ocorrem em escala mundial, e a escola tem esse papel fundamental, de ajuda-los "na sua capacidade de pensar cientificamente, de colocar cientificamente os problemas humanos".

É necessário considerar também a crise de princípios e valores que a sociedade vivencia, assim a escola assume uma função importante ao trazer valores humanos fundamentais como a justiça, a solidariedade, a honestidade, o reconhecimento da diversidade e da diferença e o respeito à vida e aos direitos humanos básicos. A escola tem um grande papel no fortalecimento da sociedade civil, das entidades, das organizações e dos movimentos sociais.

Ser professor hoje exige-se ter uma cultura geral mais ampliada, está sempre atento ao seu contexto em termos de formação, informação, atualização, ter competência para saber agir na sala de aula, habilidades comunicativas, domínio da linguagem informacional, saber usar os meios de comunicação e introduzi-los na prática no contexto educacional.

No contexto de tecnologia, às vezes, há questionamento sobre o espaço do professor, uma vez que a internet fornece informações, mas o 
espaço dessa profissão ainda permanece e permanecerá. $O$ professor através das mediações e intervenções pedagógicas se torna cada vez mais importante para a criação das condições cognitivas e afetivas, que ajudarão o aluno a lidar com todas essas informações, a desenvolver sua capacidade cognitiva e operativa, formação para a cidadania crítica e formação ética.

Essas novas exigências educacionais pedem uma nova postura do professor, que seja capaz de ajustar a sua didática às novas demandas da sociedade, do conhecimento, do aluno. Malacrida e Barros (2013, p. 79), ao realizar um estudo com professores, constatou que lidar com a tecnologia em sala de aula é um grande desafio para o professor, pois muitos se sentem concorrentes com os meios de interação, principalmente a internet, que disponibilizam o conteúdo com maior facilidade.

Então, é necessário estimular nos alunos a capacidade de filtrar os conteúdos e não assumir como verdade a primeira informação vista. A presença do professor também deve estimular a verificação e o questionamento do teor da informação. Malacrida e Barros (2013, p. 86) complementam que mesmo com todas as tecnologias disponíveis "o contato humano na relação professor-aluno é insubstituível", que é preciso acreditar na profissão docente e que é de fundamental importância também o regaste do valor e da importância do professor.

Quantificando o assunto de correção consciente e a correção de médio e longo prazo, observa-se que $100 \%$ dos Professores acreditam que a correção realizada em sala de aula (quadra, no caso) pode ajudar a criança fora da escola. Uma vez que essa correção seja feita de maneira afetuosa e o professor esteja presente integralmente dentro das aulas.

\section{Gráfico 4 - Quando em determinada situação você Professor precisa corrigir alguma ação do seu aluno, você corrige visando somente aquele momento, ou você acredita que pode ajudar na vida da criança fora da sala de aula?}

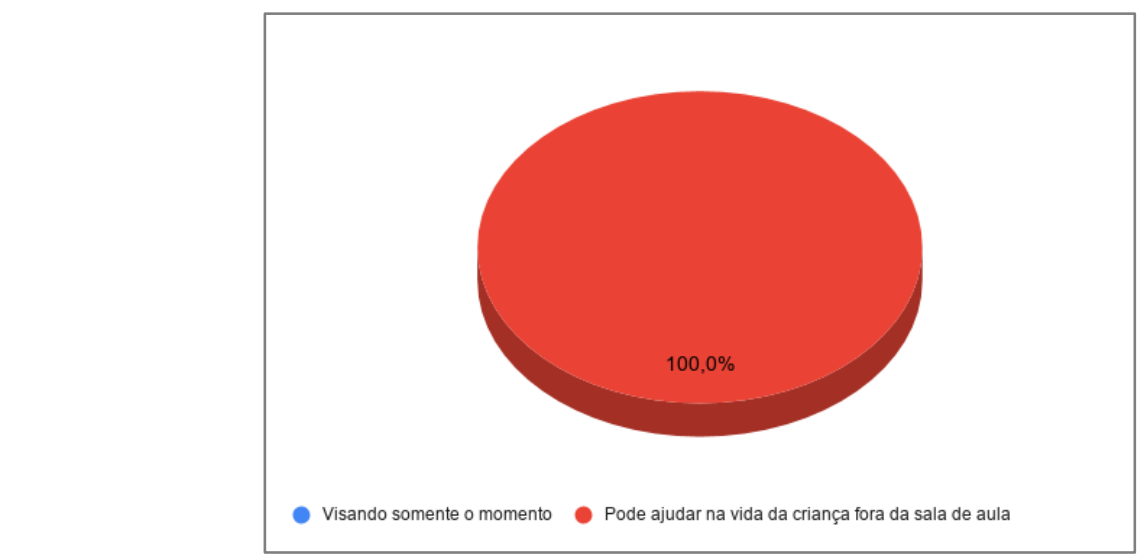

Fonte: Autores. 
A partir das respostas dos entrevistados, infere-se que a Logosofia é uma ciência que busca o desenvolvimento humano a partir do conhecimento de si mesmo, e também valorizando a superação individual, projetando conhecimento da mente, pensamentos e sentimentos para o crescimento do ser na sociedade. Conjuntamente com uma evolução consciente que educa para a vida, fazendo dela o objeto de estudo constante.

Toda e qualquer atitude de ensinar tem o dever de motivar e incentivar a busca pelo conhecimento substancial que agrega o valor adequado de apropriação e valorização do mesmo. Diante desse quadro que o Professor da atualidade deve se inspirar, pois diferente de todos os estudos anteriores o professor não se encontra no centro do conhecimento.

O aluno como personagem central do ensino e atuante na construção do próprio saber, assume uma posição aprendizado que pode torná-lo mais exposto aos processos de aprendizagens individuais. Segundo Nogaro e Granella (2004), o erro possui uma multiplicidade de conceitos. E para todo processo de aprendizagem o erro faz parte desse percurso, principalmente, na Educação Física. Pois o erro é a experiência individual que cada aluno precisa aprender e agir com ela de maneira natural.

Diante da dificuldade de aprender algum movimento, espera-se que o aluno se supere, fazendo parte de um processo de aprendizagem. Como são indivíduos em construção e a atenção da Educação Física é voltada para o movimento, o corpo que se insere no meio social faz parte do processo de aprendizagem auxiliando no conhecimento e na capacidade de buscar melhora dentro da aula. Em uma aula de Educação Física que estimule o crescimento e valorize o aluno, faz parte do cotidiano os colegas verem 0 erro dos outros e a partir disso reconhecer e valorizar o esforço. Quando se retira o foco do que foi equivocado e destaca o que foi empenhado, essa situação estimula ao aluno a possibilidade de tentativa sem se importar se foi certo logo na primeira vez ou se precisou de mais chances para alcançar o objetivo de aprender. Fundamental para a convivência em coletivo, a Educação Física se mostra como um ótimo espaço de aprendizagem para essa situação desde que os Professores não percam o foco papel central da Educação Física Escolar.

O Professor tendo uma postura mais presente em sala, permite que haja a correção individual e estimuladora, que vise valorizar o esforço de cada aluno reforçando internamente neles o conhecimento e aceitação do erro como um processo de aprendizagem. O respeito que se tem pelo outro consequentemente pode gerar uma empatia e colaboração com o próximo.

A importância da Educação Física perpassa pela socialização e superação, cumpre com os objetivos propostos pela BNCC, citados 
anteriormente, em cada uma das etapas escolares, além de trabalhar a todo momento a Cultura do Corpo, que envolve tudo que engloba o ser e seu entorno. A coletividade presente em uma aula de Educação Física não pode permitir que a superação individual seja desmotivada.

$\mathrm{Na}$ pesquisa, ao pedir para o professor que defina o significado de Logosofia as respostas se assemelham destacando palavras como: desenvolvimento humano, conhecimento de si, superação individual, evolução constante, educar o ser para vida, que são valores que o professor anseia para seus alunos. Segundo os entrevistados, a Logosofia é uma ciência que busca o desenvolvimento humano a partir do conhecimento de si mesmo, e também valorizando a superação individual, projetando conhecimento da mente, pensamentos e sentimentos para o crescimento do ser na sociedade.

Ao debater a importância da disciplina Educação Física os professores colocam a questão da socialização, pois permite ao aluno vivenciar valores, regras importantes no convívio na sociedade, o respeito com o próximo, ressaltando também a questão do ser humano se comunicar através do corpo, então é o momento do indivíduo se conhecer, conhecer seu corpo, suas limitações trabalhando aspectos físicos psicológicos.

Para a disciplina de Educação Física, o conhecimento da Logosofia facilita na correção dentro das Quadras, pois ao estar consciente em sala, a ação se torna mais afetuosa e assertiva, pois essas características são sempre destacadas na Pedagogia Logosófica, uma vez que para se evoluir conscientemente é necessário que haja a compreensão do próximo para o crescimento conjunto.

Os entrevistados concordam entre si ao colocar a importância de se trabalhar as dificuldades dos alunos, pois segundo esses professores a dificuldade favorece a construção do conhecimento, e a medida que o professor trabalha com o erro do aluno é a oportunidade de mostrar aos mesmos que os erros fazem parte do processo de aprendizagem, e que é possível trabalhar para superar os mesmos.

Sabe-se que a Educação Física é uma disciplina que se destaca por trabalhar a Cultura Corporal do Movimento, individual, o coletivo, suas habilidades, capacidades entre outros mais. Uma aula que exige dos alunos percepções individuais e coletivas, o professor então deve evitar expor o aluno a situações constrangedoras que possam gerar experiências negativas que limitem a possibilidade de que o aluno explore seu próprio campo experimental desenvolvendo essas percepções. Essa situação exigirá do professor uma prática que seja capaz de trabalhar essas limitações, e a Pedagogia Logosófica com a conscientização dessa prática. 


\section{REFERÊNCIAS}

BETTI. I. C. R. Ensino de primeiro e segundo graus: educação física para que? Revista Brasileira de Ciências do Esporte, v. 3, n.2, p. 282-287, 1992.

BETTI. I. C. R. Educação física escolar: a percepção discente. Revista Brasileira de Ciências do Esporte, v. 16, n.3, p.158-167, 1995.

BETTI. I. C. R. Educação física escolar: uma proposta de diretrizes pedagógicas. Revista Mackenzie de Educação Física e Esporte, ano I, n. I, 2002.

Conceitos Da Pedagogia Logosófica. Disponível em: http://www.logosofia.org.br/logosofia/conceitos.aspx. Acesso em: 14 mar. 2019.

CUNHA, Maria Isabel da. O bom professor e sua prática. 24. ed. Campinas: Papirus 2011. 159 p. (Coleção Magistério: formação e trabalho pedagógico).

D’ÁVILA, Maria Cristina; VEIGA, Ilma Passos A. (Orgs.). Profissão Docente: Novos sentidos, novas perspectivas. Ilma Passos Alencastro Veiga; Cristina Maria D'Ávila (orgs.). 2 ed. Campinas, SP: Papiros, 2012. (Coleção Magistério: Formação e Trabalho Pedagógico).

DAOLIO, Jocimar; OLIVEIRA, Rogério Cruz. Educação Física, prática pedagógica e não-diretiva: a produção de uma "periferia da quadra". Educação em Revista. v. 30, n. 02, p.71-94, Abril - Junho. Belo Horizonte, 2014.

FILHO, Daniel Carreira. Qual o significado da Educação Física Escolar. Disponível em: https://blogs.gazetaesportiva.com/danielcarreirafilho/qual-osignificado-da-educacao-fisica-escolar/. Acesso em: 15 mar. 2019.

FREITAS, Angela Maria Ribeiro. Íntegra da palestra de Angela Maria Freiras. Pedagogia Logosófica. 31 janeiro 2017. Disponível em: https://www.youtube.com/watch?v=J779en1hbYM\&t=1386s. Acesso em: 30 jul. 2019.

GAYA, A.; GAYA, A. Jogos Desportivos: Formação e investigação. In: Nascimento, J. V. do.; Ramos, V.; Tavares, F. Coleção Temas em Movimento. Florianópolis: UDESC, 2013.

GOMES, Ana Lucia. Tecnologia em sala de aula: a inovação do ensino através da aprendizagem 3D. Revista Educação e Cultura Contemporânea, v. 11, n. 25. 2014.

GONZÁLEZ PECOTCHE, Carlos Bernardo. A arte de ensinar e a arte de aprender (1 a parte) - Introdução ao Conhecimento Logosófico. Tradução de Filiados da Fundação Losófica. 3. ed. São Paulo: Logosófica 2011.

GONZÁLEZ PECOTCHE, Carlos Bernardo. A arte de ensinar e a arte de aprender (2ª parte) - Introdução ao Conhecimento Logosófico. Tradução de Filiados da Fundação Losófica. 3. ed. São Paulo: Logosófica, 2011.

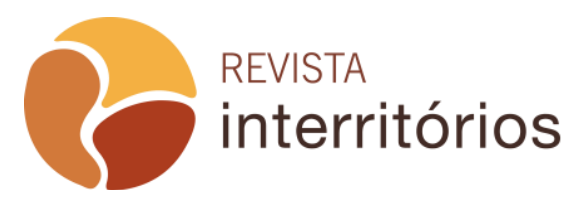

Interritórios | Revista de Educação Universidade Federal de Pernambuco, Caruaru, BRASIL | V.5 N.9 [2019] 
GONZÁLEZ PECOTCHE, Carlos Bernardo. Coletânea da Revista Logosofia, tomo 2. Revisão da tradução José Dalmy Silva Gama. 2. ed. São Paulo: Logosófica, 2012.

GONZÁLEZ PECOTCHE, Carlos Bernardo. Deficiências e propensões do ser humano. Traduzido do espanhol por Filiados da Fundação Logosófica. Revisão da tradução José Miranda de Oliveira. 13. ed. São Paulo: Logosófica, 2012.

GONZÁLEZ PECOTCHE, Carlos Bernardo. Logosofia: ciência e método: técnica da formação individual consciente. 12. ed. São Paulo: Logosófica, 2013.

GONZÁLEZ PECOTCHE, Carlos Bernardo. Exegese Logosófica. Tradução: Colaboradores voluntários da Fundação Losófica (em Prol da Superação Humana) 12. ed. São Paulo: Logosófica, 2016.

IMBERNÓN, Francisco. Formação permanente do professorado: novas tendências. Tradução de Sandra Trabucco Valenzuela. São Paulo: Cortez, 2009.

KÖCHE, José Carlos. Fundamentos de metodologia científica: teoria da ciência e iniciação à pesquisa. Petrópolis: Vozes, 2011.

LIBÂNEO, José Carlos. Adeus professor, adeus professora?: novas exigências educacionais e profissão docente . 12. ed. São Paulo, SP: Cortez, 2010. 102 p. (Questões da nossa época; 2). ISBN 9788524915949 (broch.).

LIMA, Ana Clara Ramalho Evangelista. Caminhos da aprendizagem da docência: os dilemas profissionais dos professores iniciantes. In: Profissão Docente: Novos sentidos, novas perspectivas. IIma Passos Alencastro Veiga; Cristina Maria D’Ávila (orgs.) 2 ed. Campinas, SP: Papiros, 2012. (Coleção Magistério: Formação e Trabalho Pedagógico). p. 135-150.

LUCKESI, Cipriano Carlos. Avaliação da aprendizagem escolar: estudos e proposições. 22 ed. São Paulo: Cortez, 2011.

MALACRIDA, Vanessa Ananias; BARROS, Helena Faria De. Ser professor no século XXI: representações sociais de professores. Jundiaí, Paco Editorial: 2013.

MOREIRA, Marco Antônio. Teorias de Aprendizagem. São Paulo: EPU, 1999.

NEIRA, Marcos Neira. Íntegra da palestra de Marcos Garcia Neira. A Educação Física na BNCC. 17 junho 2017. Disponível em:

https://www.youtube.com/watch?v=J779en1hbYM\&t=1386s. Acesso em: 15 mar. 2019.

NOGARO, Arnaldo; GRANELLA, Eliane. O erro no processo de ensino e aprendizagem. Revista de Ciências Humanas. v. 5, n. 05. 2004.

O que é Logosofia. Disponível em: http://www.oqueelogosofia.com.br/. Acesso em: 14 mar. 2019.

Pedagogia Logosófica. Disponível em: http://www.logosofia.org.br/logosofia/pedagogia.aspx. Acesso em: 14 mar. de 2019.

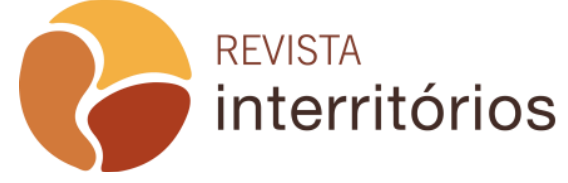

Interritórios | Revista de Educação Universidade Federal de Pernambuco, Caruaru, BRASIL | V.5 N.9 [2019] 
REZER, Ricardo; FENSTERSEIFER, Paulo Evaldo. Docência em Educação Física: reflexões acerca de sua complexidade. Pensar a Prática, São Paulo, v. 11, n.3, p. 319-329, set./dez. 2008.

SOARES, Carmen Lúcia. Educação física escolar: conhecimento e especificidade. Revista Paulista Educação Física, São Paulo. Supl. n. 2, p. 6-12. 1996.

TARDIF, Maurice. 0 trabalho docente: elementos para uma teoria da docência como profissão de interações humanas. Maurice Tardif; Claude Lessard. Tradução de João Batista Kreuch. 4. ed. Petrópolis, RJ: Vozes, 2008.

TREVISAN, Rita. Bncc de Educação Física: Confira as seis unidades temáticas. Disponível em: https://novaescola.org.br/bncc/conteudo/110/bncc-de-educacaofisica-confira-as-seis-unidades-tematicas. Acesso em: 23 ago. 2019.

VEIGA, Ilma Passos Alencastro. Docência como atividade profissional. In: Profissão Docente: Novos sentidos, novas perspectivas. Ilma Passos Alencastro Veiga; Cristina Maria D’Ávila (orgs.) 2 ed. Campinas, SP: Papiros, 2012. (Coleção Magistério: Formação e Trabalho Pedagógico). p. 13-22.

ZWICKER, Melanie Retz Godoy dos Santos. A aprendizagem ativa e o cérebro: contribuições da neurociência para uma nova forma de educar. In:

Aprendizagem ativa: Contextos e experiências em comunicação. Bauru: Universidade Estadual Paulista, Faculdade de Arquitetura, Artes e Comunicação, 2017. p. 49-74. 